Caring collectives and other forms of bystander helping behavior in violent situations

Bloch, Charlotte; Liebst, Lasse Suonperä; Poder, Poul; Maria Christiansen, Jasmin ; Heinskou, Marie Bruvik

Published in:

Current Sociology

DOI:

$10.1177 / 0011392118776365$

Publication date:

2018

Document version

Peer reviewed version

Document license:

Other

Citation for published version (APA):

Bloch, C., Liebst, L. S., Poder, P., Maria Christiansen, J., \& Heinskou, M. B. (2018). Caring collectives and other forms of bystander helping behavior in violent situations. Current Sociology, 66(7), 1049-1069.

https://doi.org/10.1177/0011392118776365 
This is the accepted manuscript (post-print version) of the article. In terms of content, the post-print version is identical to the final published version, but there may be differences in typography, layout and language edits.

Please cite the published version:

Bloch, Charlotte, Lasse S. Liebst, Poul Poder, Jasmin M. Christiansen, \& Marie B. Heinskou. 2018. "Caring collectives and other forms of bystander helping behavior in violent situations." Current Sociology 66(7): 1049-1069.

doi.org/10.1177/0011392118776365

\section{Caring Collectives and Other Forms of Bystander Helping Behavior in Violent Situations}

Charlotte Bloch ${ }^{1}$, Lasse Suonperä Liebst ${ }^{1 *}$, Poul Poder ${ }^{1}$, Jasmin Maria Christiansen ${ }^{1}$, and Marie Bruvik Heinskou ${ }^{2}$

${ }^{1}$ Department of Sociology, University of Copenhagen

${ }^{2}$ Hans Reitzels Forlag, Copenhagen

* Corresponding author: 1s1@soc.ku.dk

Abstract

Social science research has traditionally described bystanders in violent emergencies as being passive. Recent evidence, however, stresses that bystanders typically intervene proactively and successfully in violent, dangerous emergencies. This paper examines the multiple ways bystanders act in situations of violence, with the aim of moving beyond the understanding of bystanders as being either passive or active. Based on a qualitative analysis of surveillance camera recordings of urban public assaults, we map different types of bystander behaviors as they unfold in real-life violent events. The first part of the analysis is summarized in a typology that covers three types of bystander action: distancing, ambivalence, and involvement. In the second part, we show that the 
involvement action also unfolds through coordinated interactions between the bystanders, what we characterize as a 'caring collective.' This interactional aspect of bystander involvement has rarely been examined in the bystander literature, which tends to focus on individual bystander action and motivation.

Keywords: bystanders; violence; video analysis; micro-sociology

\section{Introduction}

Research on bystanders has mainly considered bystanders as passive.

This view is based on the well-known 'bystander effect,' suggesting that the presence of other bystanders implies a diffusion of responsibility and thus inhibits the likelihood for intervention (Darley and Latané, 1968). Recent meta-analytical evidence, however, challenges this view by showing that the bystander effect attenuates, or even reverses, in high-danger, violent emergencies (Fischer et al., 2011). That is, in situations of violence, additional bystanders do not diffuse the responsivity for helping but rather provide a welcome support that increases the likelihood of intervention.

Another characteristic of the bystander research field is its methodological focus on quantification. This has the implication that bystander behavior has mainly been examined deductively from a set of predefined behavioral categories, constructed so as to suit statistical analysis. This involves a risk of overlooking unexpected bystander behaviors that fall outside the predefined categories and statistical modelling assumptions. Thus, most bystander literature assumes a priori that bystander behaviors can be sorted into a binary distinction between active and passive, or alternatively, escalatory and de-escalatory acts (Levine et al., 2011). Furthermore, because of the statistical modelling techniques being used, the research has tended to focus on individual bystander action and motivation rather than interactional processes between the bystanders. This reflects how the interactional nature of face-to-face encounters tends to be considered a misspecification in most statistical models that assume independence between individual actions and observations (Abbott, 1988). Thus, across the literature, very few studies have examined how bystander behavior is shaped by social interaction processes. 
Within the last years, scholars have advocated that video data offer a methodological means to improve the ecological validity of bystander research (Lindegaard and Bernasco, 2018). For example, studies based on video surveillance footage provide compelling evidence that bystanders tend to act prosocially in real-life violent emergencies (Levine et al., 2011). However, an important yet underappreciated methodological prospect of video data is how it allows for a qualitative explorative approach to the study of bystander behavior. Given this opportunity, the current study offers a qualitative and open-ended mapping of the various behaviors that bystanders employ in violent emergencies. The present study is one of the first qualitative examinations of bystander behavior based on surveillance camera footage.

Taken together, the purpose of this paper is to explore the methodological possibilities of video data for an exploratory analysis of the diverse expressions of bystander actions and interactions. Specifically, we seek to answer two research questions: How do bystanders act in the violent situation; and what interactional processes develop between the bystanders and shape their involvement in the violent situations? In answering these questions, we add to the existing knowledge by showing that bystanders act and interact in ways that expand the behavioral repertoire beyond the predefined categories that are typically assumed in bystander research.

\section{Data and methods}

Data was a sample of surveillance camera recordings of violent incidents in urban public places. ${ }^{1}$ Copenhagen Police Department provided us access to all terminated police cases concerning violent assaults from the central police districts of Copenhagen between 2010 and 2012. This sample covered 933 cases, of which 164 contained video surveillance clips of varying quality and relevance for the present study.

For our analysis, we selected video clips on the following criteria. (1)

Given our focus on bystander behavior, the clips needed to include bystanders witnessing the violent event. (2) Similar to Levine et al.'s (2011) bystander study, we

\footnotetext{
${ }^{1}$ The current study was approved by the Danish Data Protection Agency (file number 2015-57-01250026).
} 
excluded clips where the situation was handled by door security personnel (i.e., bouncers). (3) The video clips were attached to paper based police case files that contained in-depth situation descriptions; as we will describe below, this data triangulation with police case data allowed us to compensate for some of the limitations of the video data. (4) The clips had a technical recording quality (e.g., resolution, brightness) that allowed for a detailed analysis of the observed bystander behaviors. (5) The video clips captured the duration of the interaction sequence with no or only negligible breaks. This latter criterion of 'complete capture' (Nassauer and Legewie, 2016) was particularly important in the current analysis, because we are interested in the interactional phases of the bystanders' behavior. In sum, we selected 14 cases for analysis, as these were sufficient to achieve data saturation, that is, a redundancy in the observed behavioral patterns (Grady, 1998). The selected videos covered between 2 and 25 minutes of interaction.

The growing scholarly interest in video data across the social sciences (Lindegaard and Bernasco, 2018) is closely linked to the increasing availability of highquality video footage — a technical development which, for example, Collins (2008: 5) embraces with the argument that a "video revolution has made available much more information about what happens in violent situations than ever before." This methodological optimism relates to the fact that video data provide scholars with a detailed picture of how violent situations actually unfold. Video-recorded interaction sequences can be replayed, slowed down to the split second, and copied so that several scholars can easily cross-check each other's observations. Therefore, video methods provide scholars with a high-precision 'microscope' to explore dynamics of the social micro-world (Scheff, 1994), as well as subconscious processes of bodily microinteraction (Collins, 2008).

Accordingly, video observation techniques have several advantages over self-reported accounts of behavior in violent events, which is known to have a low validity, as well as over on-site observation, where the observer only has one chance to record everything and no opportunity to correct records (Vrij et al., 2014; Philpot, 2017). In our experience, this latter issue is particularly problematic in the observation of violent events where it is difficult to sustain one's focus on non-spectacular actions: 
One's eye tends to be caught by the drama — the violent epicenter of the event - at the expense of the more unheeded, non-violent behaviors.

Despite these advantages, the application of video observation techniques faces several challenges. First, given that this is a relatively new approach, there exist few guidelines for how to transcribe video observed behaviors (Lindegaard and Bernasco, 2018). In the present study, a subset of the visual video data was transformed into detailed behavioral descriptions of the actions between participants, and these descriptions are in turn presented as empirical documentation for our analytical observations. Further, given that it can be hard to visualize the interaction sequences from these dense behavioral transcripts, we decided to supplement our analysis with a number of graphical representations, illustrating how the bystanders interact across time and space. As an alternative to these graphical representations, data could have been presented in one or several screen-shots (Collins, 2008). However, similar to other video studies (Lindegaard et al., 2017), the police only provided us access to the video clips under the anonymity condition that no pictures could be published.

Second, sounds are typically not recorded by surveillance cameras, and also in our case, the clips provide no explicit information on the verbal communication of participants. Although this limitation should not be exaggerated-given that a substantial proportion of human communication is nonverbal (Burgoon et al., 2011) scholars relying on surveillance camera footage should consider supplementing their analysis with other data containing information on the verbal aspect. In this study, we take advantage of the fact that our video clips are linked with a police case file that contains detailed information (e.g., from witness statements) on what was said in the situation and what the conflict is about. This triangulation of video observation and selfreported accounts compensates for the weaknesses of each data type.

The video material is a complex and very rich data source that, for better or worse, allows for behavioral analysis with a high resolution. Thus, simply because it is possible, it is tempting to base the analysis on the smallest identifiable units of human bodily movement. However, as von Cranach and colleagues suggest, such an approach where data are analyzed from the 'bottom up' can easily lead to "difficulties because the 'smallest units' contain no instructions for synthesis" (von Cranach et al., 1982: 167). 
That is to say, there is no easy way to decide how small-scale physical movements of the body form into socially meaningful actions.

Therefore, it is recommended that scholars also apply a 'top down' perspective by which the observed behavior is interpreted as higher order units that carry social meaning. In this view, social meaning plays a key role in behavioral observation, because this is what allows the researcher to segment "the stream of behavior into meaningful units on the level of acts" (Valach et al., 1988: 255). In this process, the researcher is encouraged to use a certain amount of intuition about the social meaning of the observed behaviors, especially if, as in our case, the researchers and the studied actors are part of the same communication culture. Further, theory plays a key role in this approach, because it is recognized that all behavioral observations involve some degree of perceptual interpretation on the part of researchers. In the present study we draw, as we will return to later, on Collins' (2004) 'interaction ritual theory' in our interpretation of the video observed bystander behavior.

Following these considerations, in our analysis, an act of bystander involvement is not aggregated from its manifestation in mere physical movements (e.g., a bystander raises the arm 90 degrees from the body, with an open palm, etc.). Rather, we used a combination of social intuition, micro-sociological theory, and scholarly familiarity with the object of research when we perceived this act top down - that is, as socially meaningful bystander involvement aimed at inhibiting further aggression.

It should be recognized that this top down approach risks imputing erroneous social meaning to the analyzed behaviors. One means of minimizing this risk is to utilize the fact that video data makes it easy for several researchers to cross-check each other's behavioral records. Accordingly, in the current study the videos were analyzed by two researchers, a trained student assistant and the first author, who crosschecked their observations and interpretations through continuous dialogue. This researcher triangulation is also important because the video-recorded events often unfold rapidly, with an associated risk that a single researcher could overlook important behavioral micro-details.

The two researchers' analysis of the video clips progressed in several steps. In an initial analysis of the 14 selected videos, we identified what types of behavioral reactions the bystanders express across the situations, including the caring 
collective interaction type. On this basis, we selected 3 cases which were exemplary for the caring collective interaction type. We then conducted a detailed behavioral description of these cases (see Scheff, 1994), with the aim of identifying the interactional phases and processes that underpin the emergence of the caring collectives. In conducting the behavioral descriptions, each bystander's visual appearance, and the chronological order of the bystander's behaviors, were described to ensure that the bystanders were not mixed up. Our main results are based on the in-depth analysis of the 3 selected cases, and to support and illustrate our analytical observations, we present extracts of the behavioral descriptions from 2 of these cases.

Further, to validate our findings, we described an additional 4 cases and compared whether the manifestation of the caring collective in these cases agreed with our analytical observations. Finally, we looked systematically into the contrasting cases in which the caring collective did not emerge (King et al., 1994)-by comparing these negative cases with the positive, we were able to pin down some of the situational background conditions for the emergence of the caring collective.

\section{Bystander action}

In this section, we illustrate how bystanders employ a diversity of actions that challenge the assumption that bystander action is structured along a binary passiveactive axis. We outline three broad categories of bystander action-i.e., expressing distancing, ambivalence, and involvement, respectively - and each of these categories is illustrated with behavioral transcripts from the video data.

\section{Actions expressing distancing}

Actions that included visible signs of active registration of violence, followed by people passing by or moving away from the scene, were interpreted as distancing actions. Distancing actions were largely actions that sought to increase the physical distance to the victim. The following transcript illustrates this bystander action type:

The violent perpetrator has pulled the victim down with him and both are lying on the ground. Britta, a bystander who is a stranger to the conflict participants, comes walking 
along the street in the direction of the violent encounter and changes her course trajectory to go around it. She walks close to the house wall on the opposite side of the street and away from the site. (...) Another bystander, also a stranger, John, passes by the attack on the street and looks towards the assault, but without stopping. He continues further along the street and away.

In the example, Britta and John both register the violent encounter ahead and seek active physical distance by changing their route and trying to avoid the victim and perpetrator.

\section{Actions expressing ambivalence}

Being a bystander to violent emergencies can be perceived and felt as a risky affair (Fischer et al., 2011) promoting escape reactions, as illustrated by the distancing actions. However, violent events can also induce sympathy and, in turn, helping and protecting behaviors. These contradictory emotional action tendencies may form the background of the bystanders' expression of ambivalent actions. In the empirical material, the following action patterns were interpreted as an expression of ambivalence: hesitating between proximity and distance to the violent situation; unrest; fidgeting near the scene; restlessness that indicates that the bystander is experiencing discomfort; and passive surveillance, such as keeping an eye on the victim and the situation, and remaining present but without getting involved. Ambivalence thus manifests itself as a passive imprisoning by the situation. The following two transcripts are examples of ambivalent bystander actions:

Rasmus walks a few steps away, stops and stands with his hands in his pockets looking at the assault. (...) Then, he walks restlessly back and forth, and often stops close to the victim and the bystanders who are leaning over the victim. He stands near the victim, but still further away than the other bystanders involved. (...) Eventually, Rasmus walks away from the victim and fades out of the picture.

Dennis walks in a wide arc around the victim and Sofie at the same time as he approaches them. (...) He has now come close to Sofie and the victim. Here he stops 
and looks at them without making contact with either of them. (...) Dennis stands with his hands in his pockets watching. (...) Then, he follows carefully after Tobias towards the kiosk, and stands a few steps from the doorway, still with his hands in his pockets. (...) Dennis walks restlessly back and forth at the kiosk entrance and looks over at the victim and Sofie.

In the first transcript the bystander, Rasmus, is showing ambivalence by moving toward and away from the victim several times. A similar pattern is seen in the second transcript where Dennis oscillates restlessly and passively back and forth in the vicinity of the violent episode.

\section{Actions expressing involvement}

Direct bystander involvement is expressed in a variety of actions that were categorized in the following sub-categories: physical intervention vis-à-vis the perpetrator to stop violence; practical actions vis-à-vis the police; collective-generating actions vis-à-vis other bystanders; and caring actions vis-à-vis the victim.

Physical intervention vis-à-vis the perpetrator to stop violence. Violence is a bodily assault and verbal inventions may be ineffective to stop it. Physical intervention may be needed to effectively halt an act of violence. In our material, physical interventions were performed with the following bystander actions: running towards the victim or perpetrator; stretching hands towards the perpetrator in a warding off gesture; trying to separate the victim and perpetrator; keeping the perpetrator away from the victim; shoving the perpetrator; and shouting and running after the perpetrator. The following transcript illustrates this type of bystander involvement, focused on the warding off gestures and the attempt to separate the perpetrator and victim. In the transcript, a young man is assaulted by two young men, an early morning in inner Copenhagen. The victim's friend and a random bystander play a crucial role in bringing the attack to a halt:

A friend of the victim, Kristina, becomes aware of how the situation is escalating and runs directly into the middle of the conflict with her arms outstretched to ward off the attack. Two young men, perpetrators 1 and 2, jump on the victim and take turns to 
knock him down and hold him while the other kicks him in the head. (...) Kristina's initial attempt to stop the attack does not work, however, and instead she takes hold of perpetrator 1's waistband to pull him away from the victim. Perpetrator 2 runs away from the site, but perpetrator 1 still keeps hold of the victim, who now lies unconscious on the ground, and continues to beat the victim with a clenched fist. Kristina lets go of perpetrator 1's waistband and instead grabs his jacket collar and tugs at this to get him to drop the victim. A random bystander, Markus, who does not know Kristina or the victim in advance, comes walking further up the street and now starts running towards the assault to intervene. When Markus reaches Kristina and perpetratorl, the perpetrator releases the victim and wriggles out of Kristina's grasp.

The description illustrates how Markus, a stranger to the persons involved, comes running, an act that seems to make the second perpetrator run away. Further, the situations shows how Kristina, spontaneously, puts herself defensively between the perpetrators and the victim, and when this action fails, resorts to a powerful physical intervention and attempts to drag the perpetrators away from the victim. Given the forceful nature of her intervention, it is noteworthy how Kristina illustrates the finding in the literature that bystanders are rarely physically victimized (Liebst et al., 2018). Kristina's intervention is emotionally costly, however, as we shall see in below description of how she shakes uncontrollably in the aftermath of the conflict. This reaction reflects how involvement in violent conflict may be associated with acute feelings of stress and fear (Collins, 2008; Heinskou and Liebst, 2016).

Practical actions vis-à-vis the police. Incidents of violent assaults are not only punishable by law but are also perceived as a violation of the public interaction order (Goffman, 1971). The bystander actions described above can be seen as one way of restoring the interaction order of the street, and the bystander actions vis-à-vis the police can be interpreted as serving the same order restoring purpose. This subcategory of bystander action involves the following practical, cooperative actions: summoning the police by telephone; helping the ambulance crew; keeping other bystanders away from the victim; gathering the victim's belongings; coming forward as a witness or informing the police; and capturing and detaining the perpetrator. The next two transcripts illustrate this intervention subcategory: 
Markus turns around and grabs Nicolaj's arm. Nicolaj is still standing over the victim, although the paramedic has tried to push him away. It is unclear whether Markus asks Nicolaj to remove himself, but the interaction results in Nicolaj moving away from the victim and thus makes room for the paramedic.

Stine picks up the victim's shoe and takes it over to the civilian police car. She talks briefly with the officers, but she ends up taking the shoe back with her to the other bystanders.

These examples show how bystanders offer their practical assistance in the situation: Markus supports the paramedics' treatment of the victim, and Stine makes the police aware of a shoe that was lost during the fight, possibly aimed at gathering material for future legal proceedings. The transcripts also show that when the police and paramedics arrive to the scene, the bystanders give way to these professionals as the central authorities on the ground. The bystanders continue to assist, but in a manner subordinate to the present authorities.

Collective-generating actions vis-à-vis other bystanders. As a violation of the social interaction order, violence attracts social attention and, in turn, forms a basis for shared interactional attention between the co-present bystanders. This development was visible as physical gatherings of the bystanders around the victimthat is, which we will return to later, an interactional process that we interpret as reflecting a collective-generating type of bystander actions. This subcategory of bystander involvement includes the following actions: asking for information; telling other bystanders what has happened; comforting or soothing other bystanders; and gathering physically. The next two transcripts illustrate this subcategory:

Jens, a friend of the victim, approaches the victim and Kristina, and he and Markus, like Kristina and the paramedic, bend down over the victim. A random bystander, Dorthe, stands up from the roadside, where she had been sitting looking at the incident until now, and goes towards the bystanders who are assembled around the victim. (...) Stine, another friend of the victim, stands closely bent over the victim along with Kristina and 
Jens. (...) Nicolaj, another random bystander, comes walking along the street and passes through the other bystanders and towards the victim. Stine takes a few steps away from the victim with Kristina. Stine holds Kristina, who has begun to shake back and forth, as if she is crying or is in shock.

Palle, a random bystander, comes over to Sophie and Jan, who are sitting down with the victim. He may have asked what has happened, because Jan looks up, talking and pointing with a proactive movement towards the entrance to the kiosk. Tobias and Sфren are on their way out of the kiosk, but when Jan points towards it, they turn around and go into the kiosk again. Tobias then comes out of the kiosk with his hands full of paper, brought to the victim who is bleeding.

The transcripts show how the bystanders look for information to achieve a shared understanding of what has happened. The bystanders talk together, comfort each other, and some bystanders coordinate the help of the others. Taken together, the situations illustrate how interactional closeness arises through the physical gathering.

Caring actions vis-à-vis the victim. While physical interventions are aimed at the perpetrator, caring actions are aimed at the victim. The victim of violence is a person who, most often undeservedly (but see Baumeister, 1997), has been injured physically and appears emotionally distressed. Therefore, according to Clark (1997), the victim complies with the conditions for obtaining compassion and sympathy, such as comforting and social attention from bystanders.

The following actions are interpreted as caring actions that bystanders provide to victims, typically in the aftermath of the conflict: approaching the victim; stroking or touching the victim; squatting by the victim and seeking eye contact; fetching paper to wipe the blood off; examining and questioning the victim; holding the victim's hand; staying close to the victim; supporting the victim's head in one's lap; stopping the victim's attempt to rise; supporting the victim in standing upright, and various first aid actions. In the example below, a male victim has been pushed hard from behind by another man, causing the victim to fall flat forward and hit his face on the ground. The transcript starts as the victim falls and bystanders begin to react: 
The victim of violence raises himself up on all fours and wipes his bleeding face on his sleeve. Sofie, who was with the victim when he was knocked down by the violent perpetrator, stands beside him slightly hunched, and puts a hand on the victim's shoulder while looking at him. A random bystander, Jan, goes quickly over to Sofie and the victim, and bends down to take stock of the victim's injuries. Shortly afterwards Jan straightens up and goes into the nearby kiosk, which the perpetrator disappeared into after the assault. Further up the street two other bystanders are also on their way back to the victim, Tobias on a bike and Søren on foot. Tobias cycles close to the victim and Sofie, parks his bike and looks intensely at the victim and then he also goes into the kiosk. (...) Tobias comes out of the kiosk with his hands full of paper towels. He squats in front of the victim and gives him the paper towels. (...) Then, he pats the victim's shoulder with one hand and then goes back into the kiosk again. (...) Jan comes out of the kiosk and runs to the victim; he kneels beside him and puts his arms around him while stroking the victim with both hands.

This example shows how bystanders show solicitude through body contact and attention by fetching paper towels to wipe the blood away and making comforting and patting gestures. This observation is in line with prior bystander studies showing how humans (Lindegaard et al., 2017), as well as nonhuman primates (de Waal and van Roosmalen, 1979), provide caring attention to victims of aggression - that is, a phenomenon described as 'consolation' which involves bystanders comforting victims with gentle touching and hugging in the aftermath of conflicts. However, while this consolation literature conceptualizes bystander caring in terms of a single individual's acts, our analysis shows that the bystanders' caring efforts can be differentiated into an individual subtype, described by the consolation term, and a collective subtype-i.e., what we in the next section identify as a caring collective. Before we look into this argument, let us summarize our findings so far in Table 1, outlining the typology of bystander action in violent situations. 
Table 1. Typology of bystander actions in violent situations

\begin{tabular}{|c|c|c|}
\hline Distancing & Ambivalence & Involvement \\
\hline Ignoring & Fidgeting & Practical \\
\hline \multirow[t]{3}{*}{$\begin{array}{c}\text { Increasing physical } \\
\text { distance }\end{array}$} & Passive surveillance & Physical intervention \\
\hline & & Care \\
\hline & & Collective-creating \\
\hline
\end{tabular}

\section{The caring collective}

In our analysis of the collective expression of bystander caring, we draw on Collins' (2004) interaction ritual theory and, therefore, we briefly outline this theory framework. According to Collins, social life unfolds through chains of face-to-face interaction rituals, involving four key ingredients: a bodily gathering of individuals, demarcated by a barrier to outsiders, is sharing a mutual focus of attention and an emotional mood. Further, these ritual ingredients reinforce each other through feedback effects - in particular, this unfolds via a bodily process of rhythmic entrainment by which the participants experience an elevated emotional energy and collective effervescence. Collins suggests four outcomes of this interactional process: an emotional energy in the participants; group solidarity; group membership symbols; and a group specific moral framework.

Our empirical analysis of the interactional aspects of bystander behavior suggests that the caring collective develops through four phases. Phase 1 is defined by registration and an initial establishment of a shared object of attention. Then, in phase 2, scattered and non-coordinated actions take place among the bystanders. This leads to phase 3, defined by coordination of actions and interpretations of the event. Finally, in phase 4 , a physical gathering and a sense of community occur between the bystanders. In the following, we present the analysis of two situations that illustrate the sequence by which the bystander gathering crystalizes into an interactional caring ritual in the aftermath of the violent conflicts. For consistency, we draw on the same behavioral descriptions used in the above action analyses. Further, we include a number of graphic representations that provide snapshots of how the bystanders show 
behavioral distance and proximity to the violent episode and victimized persons. The bystanders are marked with black stars and identification labels with anonymized names, while paramedics, violent persons/perpetrators, and victims are marked with labels only. Labels and stars mark the location of the person at the given time, and the white arrows indicate the person's movement trajectory. Note that, for reasons of space, we only present behavioral transcripts and graphical representations of the phases 1 and 4.

\section{Example 1}

This example takes its point of departure in a violent assault unfolding early one winter morning on Strøget, the main shopping street in Copenhagen. People are either on their way home late or have got up early. A small group of drunken young people are trying to find something to eat on the way home from town. One of them, a young man, at one point looks at two young men, also moving drunkenly down the street. The two young men are provoked by his gaze, and jump on him. As the situation escalates, one of the young man's friends, Kristina, throws herself into the attack to stop the violence. The following transcript illustrates phase 1 in the development of the caring collective, characterized by registration and an emerging shared focus:

A friend of the victim, Kristina, becomes aware of how the situation is escalating and runs directly into the middle of the conflict, with her arms outstretched to ward off the attack. Two young men, perpetrators 1 and 2, jump on the victim and take turns to knock him down and hold him while the other kicks him in the head. A random bystander, Gustav, who until now has walked 2-3 steps behind the victim, abruptly changes course as the perpetrators collide with the victim. Gustav takes a big step to the left and walks around the attack. Andreas, who also comes walking down the street behind the victim, also pulls left and walks in an arc around the attack. Two unnamed bystanders continue past the attack without stopping. A random bystander, Dorthe, squats on the ground some distance away, but now looks up and towards the assault. Kristina's initial attempt to stop the attack does not work, however, and instead she takes hold of perpetrator 1's waistband to pull him away from the victim. Perpetrator 2 runs away from the site, but perpetrator 1 still keeps hold of the victim, who now lies 
unconscious on the ground, and continues to beat the victim with a clenched fist. Kristina loses her grip on perpetrator 1's waistband, instead grabs his jacket collar and tears at this to make him drop the victim. A random bystander, Markus, who knows neither Kristina nor the victim in advance, comes walking further up the street and now starts running towards the assault to intervene. When Markus reaches Kristina and perpetrator 1, the perpetrator releases the victim and wriggles out of Kristina's grip.

This transcript shows how the victim's friend, Kristina, immediately senses that something is brewing and acts accordingly. It also shows how two bystanders, Gustav and Andreas, express their registration by going around the event and moving away from the situation (i.e., distancing). Further, the two unnamed bystanders continue without stopping, i.e., they do not register. Kristina is alone in trying to intervene until Markus joins her attempt to help and protect the victim. The transcript illustrates the process from registration and scattered actions to a first shared focus of attention. This initial interactional exchange between bystanders and victim (i.e., phase 1) are illustrated in Figure 1, showing that while some bystanders spread away from the victim, others move towards the victim to intervene. This formation of a shared focus is the first step in the formation of their collective caring for the victim.

Figure 1

Registration and initial shared attention. Phase 1 of the caring collective

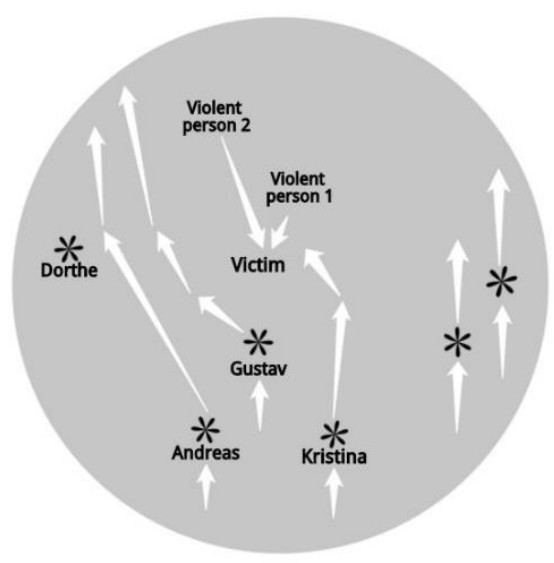


The next transcript shows how an action coordination, or a division of labor, develops from the shared focus among the bodily gathered bystanders (i.e., phase 4):

The ambulance crew emerge from the ambulance and move towards the victim. Kristina bends over the victim, who is still lying on the ground. Perpetrator 1 has run a short way back down the street, and now runs in an arc around the victim and Kristina. Markus stands near the victim and Kristina, pointing and shouting continuously at perpetrator 1 while he moves around them and away from the site. Jens, a good friend of the victim and Kristina's, approaches them and, like Kristina, he bends over the victim. Markus and the paramedic also bend over the victim. Dorthe gets up from the roadside where she had been sitting and looking until now and approaches the gathering. Margrethe and Bjarne, two random bystanders, come walking down the street together, and are also approaching the assault. Margrethe goes up close to look in among the many bystanders who have gathered around the victim. Stine, another friend of the victim's, is walking by the ambulance and looking towards the gathering of bystanders around the victim. Three unnamed bystanders continue past the assembly without stopping.

The transcription documents how the bystanders undertake various tasks: Some confront the perpetrator or protect the victim (Markus), while others take care of the victim and communicate with the paramedics (Kristina and Stine). In other examples, it is also seen that some bystanders comfort and inform other bystanders and contact the police. 
Figure 2

Gathering and coordinated actions. Phase 4 of the caring collective

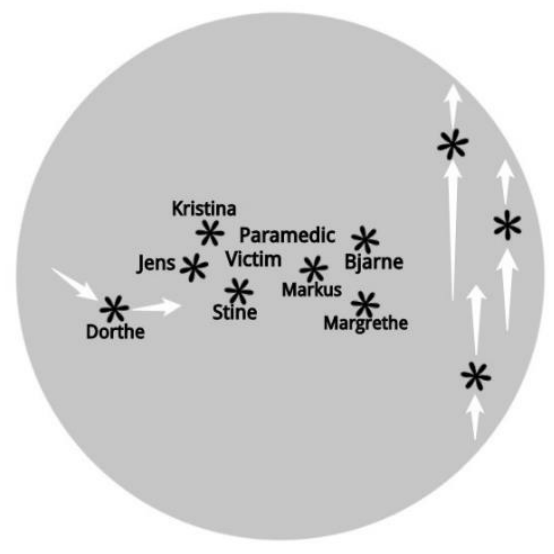

Figure 2 shows how the bystanders physically move together around the victim and coordinate their efforts. The figure also illustrates how the gathering draws more and more participants closely together around the victim, so that seven bystanders (besides the paramedics) are involved in the collective awareness concerning the victim. This is phase 4 in the formation of the collective caring ritual.

With seven people densely gathered around the victim, a demarcation with the outside world is created. Simultaneously with the formation of the gathering, three unnamed bystanders pass by - they watch and record the scene, but all continue past without stopping. The large number of bystanders and their intense shared focus seems to signal that someone is already taking care of the matter, and that therefore there is no need for more help. With that demarcation in relation to the outside world in place, the behaviorally manifest key ingredients for a successful interaction ritual are present (Collins, 2004) — the bystanders are physically gathered around the victim who is the focal point of their shared attention and coordinated actions. As the video recording ends, the young man who was kicked down by the two perpetrators has been sent off in an ambulance with his friend Jens, and a police officer and a bystander pursue the perpetrators on foot. The victim's two friends, Kristina and Stine, are standing in an almost empty street, in contrast to what they experienced shortly before.

\section{Example 2}


One early autumn morning in Copenhagen, a street is swarming with people who are on their way home from the nightlife. A man is walking and talking to a girl he has met in the city. The street is calm-however, without any warning whatsoever, a stranger pushes him hard from behind. The push causes him to fall forward and hit his face on the ground. A number of the people who are present in the street note the unprovoked push. These bystanders flock quickly to help the victim, whose face is bleeding heavily, and to detain the perpetrator, who tries to escape by hiding in a nearby kiosk. Several bystanders register the act of violence: Sofie is standing right next to the victim when he is pushed, and Tobias, who is walking up the street a bit ahead with his friend Søren, looks back over his shoulder as the victim hits the ground. Thus, a shared focus is established as the violent encounter occurs. The bystanders' behavioral registration of the event is illustrated in Figure 3 (i.e., phase 4):

Figure 3

Registration and initial shared attention. Phase 1 of the caring collective

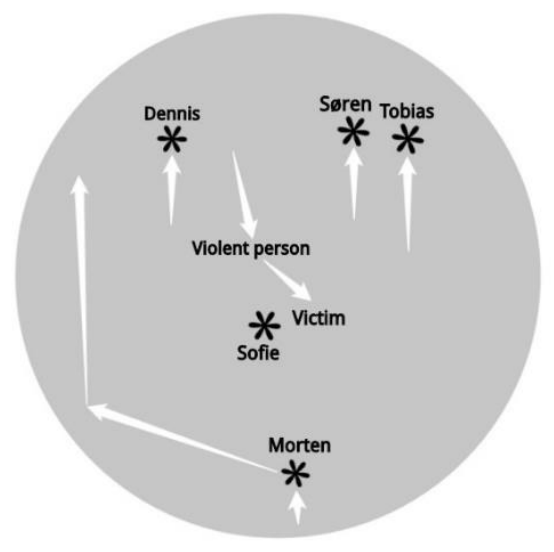

The bystanders start to act separately, without a clearly coordinated division of labor. When the perpetrator has knocked the victim to the ground, Sofie pushes him away and puts a hand on the victim's shoulder as a caring action. A random bystander, Jan, also seeks a caring acquaintance with the victim before he rushes into the nearby kiosk to find the perpetrator. Tobias and Søren move to the victim, and, like Jan, they first take stock of the victim's situation, after which they both move into the 
kiosk. Although the bystanders show no clear division of labor at this moment in time, the overlap in their actions reflects an emerging shared focus around the victim.

Shortly after, however, coordinated care work is seen as the bystanders talk together and share the caring activity between them: Some provide intimacy and comfort to the victim (Jan), while others are providing comfort to the bystander (Sofie) who was standing close to where the assault occurred. In addition to this, one bystander provides practical help by fetching some paper towels to wipe the victim's blood away (Tobias). Division of labor, bodily synchronization, and a sense of community are embodied in the bystanders' gathering around the victim (i.e., phase 4, coordinated actions and gathering):

Figure 4

Gathering and coordinated actions. Phase 4 of the caring collective

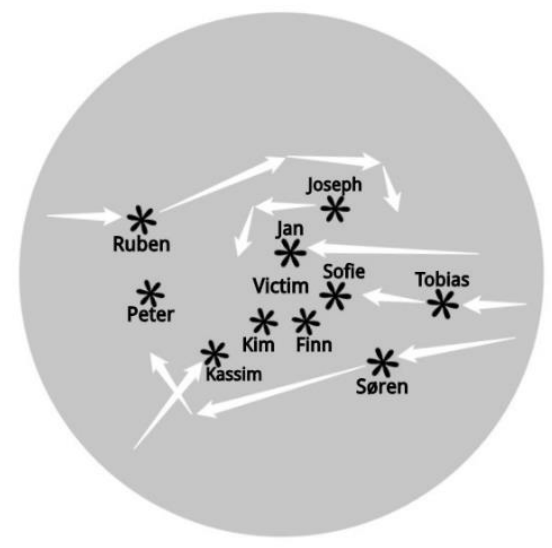

This time the video ends before the police and ambulance arrive, and as we leave the scene, the group of bystanders is still forming a ring around the victim. Some bystanders sit on the ground and talk to the victim and Sofie, and others are standing a few steps away talking together while they gesticulate vehemently and discuss the events of the last minutes.

This example shows how scattered bystander actions are succeeded by coordinated interactions between bystanders. The basis of this process is that violent incidents and victimizations stand out and, in turn, become a source of the emerging shared focus that is a key condition for interaction rituals. This point is stressed by the 
fact that the caring collectives rarely develop in more ambivalent situations, without the presence of victims who clearly appear injured (e.g., the victim is bleeding or is holding onto a body part that has been hit). This finding is in line with bystander research showing that visual cues of distress annul potential ambiguity of whether bystander help is required (Solomon et al., 1978). Without these cues of distress, the situation would lacks a visual epicenter for the bystanders' collective attention, and there would be less need for bystanders to show their collective sympathy with the victim (Clark, 1997).

Moreover, the graphical representation highlights how the bystanders' bodily gathering, both in terms of the number of people present and the spatial formation of gathering, is a precondition for the interactional coordination. First, the division of labor that defines the caring collective can only take place if there is a sufficiently large number of bystanders present among whom the labor can be divided. This condition is easily fulfilled in the majority of our cases, which are taking place in crowded night-time drinking settings (e.g., there are 27 and 19 bystanders present in case examples 1 and 2 of the caring collective, respectively). At this point, our findings are in line with Fischer et al.'s (2011) meta-analytical finding that the presence of other bystanders increases — rather than decreases (cf. the bystander effect hypothesis) — the likelihood of intervention in violent emergencies. Further, our argument is closely associated with Greitemeyer and Mügge's (2015) suggestion that additional bystanders promote intervention in emergencies where the task at hand needs to be handled by more help-givers.

Second, in terms of the spatial formation of the bystander gathering, a key characteristic of the caring collective is how the bystanders gather to form a crescent shape around the victim. This spatial interaction pattern facilitates a focused gathering, and is similar to what Goffman described as "an eye-to-eye ecological huddle that maximizes each participant's opportunity to perceive the other participants' monitoring of him" (Goffman, 1961: 18). This corresponds to the ritual ingredients of bodily co-presence, barriers to outsiders, and shared focus of attention, in Collins' (2004) interaction ritual theory. Further, the crescent shape of the caring collective is consistent with Milgram and Toch's (1969) observation that the natural form of a spectator crowd is the ring, with the object of focus in the center of the ring. 
Summarizing examples 1 and 3 in theoretical terms, our analysis suggests that key ingredients of a successful interaction ritual are present in the caring collective situations: The bystanders are bodily gathered in a circle formation supporting a shared focus of attention, shielded from outside disturbances. Given the body of evidence supporting the generalizability of interaction ritual theory across highly different contexts (Heinskou and Liebst, 2016), it is plausible to assume that the presence of these ritual ingredients promotes an emotional energy in the involved bystanders: The more bodily synchrony, interactional coordination, and shared focus there is in such situations, the more emotional energy individuals tend to experience.

Collins (2004) makes a distinction between 'formal' rituals, characterized by rigid group boundaries and interactional rules, and 'natural' rituals, which unfold more informal and spontaneous, and have fluid group memberships. In view of this distinction, the caring collective can be characterized as a natural interaction ritual: It emerges spontaneously among co-present bystanders who share a highly fluid group membership, and coordinate their interactional involvement, without any formally defined rules for how this should be done.

We believe that the term 'caring collective' grasps the interactional nature of this ritual: It is caring because it reflects an attempt to protect and sooth the distressed victim, and it is collective because this spontaneous helping behavior unfolds through coordinated interactions between the co-present bystanders. By highlighting how the caring collective emerges as an interactional process between the bystanders, we add a nuance to the bystander literature that tends to focus on the influence of gender-composition on caring behavior, and specifically suggests that women are more emotionally supportive than men in how they provide help (Eagly, 2009; Lindegaard et al., 2017). In our material, however, the division of labor in the caring collectives cannot be accounted for in terms of a gender-difference. This is illustrated in the above example where the male bystanders (Jan, Tobias) cooperate in providing care to distressed individuals.

\section{Discussion and conclusions}

The purpose of this study was to explore the diverse ways in which bystanders act and interact in violent emergencies. Our results highlight that real-life 
bystander behavior cannot be fully grasped by a binary distinction between passivity and intervention proactivity. The existence of hesitant, shifting, and often ambivalent behaviors stresses that the bystander research would benefit from reassessing and broadening its behavioral categories. Bystanders are not merely passive and exceptionally active, but are also - as summarized in our empirically extracted action typology — engaged in distancing, ambivalent, or more direct forms of involvement, aimed at stopping the violence or providing care for victims. Further, our analysis highlighted a key difference between the actions expressing distancing, ambivalence, and involvement: While distancing and ambivalence are expressed as an individual bystander action, we suggest that the involvement action can be differentiated into an individual action and a collective interaction subcategory, respectively.

In the second part of the paper, we focused on the interactional expression of involvement in caring collectives. This analysis showed that bystanders may engage themselves in spontaneous interaction rituals characterized by collectively coordinated efforts to provide care for victims. This interaction ritual process enters into force when the everyday interaction order breaks down, as illustrated by the bystanders' effort to stop the violent perpetrator, their helping the law-enforcement officials, and collective care for the victim and what is morally right. That is, in these violent emergencies, the urban interaction rule of treating strangers with 'civil inattention' (Goffman, 1971) is temporally suspended by bystanders' caring attention for the victim and violated societal norms. Taken together, these findings are in line with microsociological studies suggesting that individuals are continuously involved in the maintenance and social repair work of the everyday interaction order (Goffman, 1971; Collins, 2004).

In our analysis of the caring collective, we assumed - based on Collins' interaction ritual theory - that emotional energy is aroused as the bystanders establish a shared focus and collectively assist the victim. A further exploration of this emotional process could examine empirical indicators of emotional energy. Collins (2004) highlights mutual eye contact and erect body postures as visual cues of emotional energy, and indications of emotional energy could also be based on self-reported accounts of bystanders. 
With this study, we hope to have illustrated the methodological value of applying video surveillance footage in bystander research. Video observational techniques are suited to grasp interactional micro-details, and we could not have reached our conclusions concerning bystander behavior if we had had to rely on on-site observations or self-reported accounts. As a rule, it is only after the video-recorded situations have been observed many times, in slow-motion by several researchers, that one realizes what is going on. Further, interviews with the participants would, at best, provide a crude picture of the actual behaviors, given that the bodily aspect of social and, in particular, violent behavior cannot be easily verbalized by the persons involved (Collins, 2008).

However, video footage data also has its own limitations; in the Methods section, we mentioned the absence of sound and guidelines for transcribing video data. In addition to these limitations, video data provides limited information on the inner thoughts and feelings of participants, as well the social chains of events and relationship ties that proceed the violent situation. Following recent methodological discussions on the use of video footage in research of violent events (Lindegaard and Bernasco, 2018), we attempted to compensate for these limitations by triangulating our video data with police case data. However, we recognize that this only provides a partial solution to the limitation of our video data (e.g. emotions are rarely described in police files), and future bystander studies should prioritize triangulation of video data with several other data sources (e.g., police case files and interviews with participants).

A final, and perhaps most serious, limitation of video surveillance data relates to the fact that our sampling frame only covers police-reported events - and thus is biased towards more serious incidents of violence where the bystanders were unsuccessful in preventing the violence from occurring at all (King et al., 1994). Other types of bystander behaviors than the ones observed in the current study are thus likely to be found in video data that includes non-reported cases, given that such cases would include less severe and more symmetrical kinds violence (e.g., organized fights, see Jackson-Jacobs, 2013), and thus, in turn, fewer severely victimized individuals in need of care. In one of the literature's few qualitative bystander studies, Levine et al. (2012) show how bystanders play a key role in self-policing aggressions among their friendsthese incidents are rarely police-reported and this kind of bystander self-policing is 
accordingly underrepresented in our data sample. Taken together, the external validity of our findings is strongest with regard to urban public emergencies involving severe, police-reported violence, and future bystander research should prioritize sampling incidents unreported to the police (Lindegaard and Bernasco, 2018).

\section{References}

Abbott A. (1988) Transcending general linear reality. Sociological theory 6: 169-186.

Baumeister RF. (1997) Evil: Inside human violence and cruelty, New York: W.H. Freeman.

Burgoon JK, Guerrero LK and Manusov V. (2011) Nonverbal Signals. In: Knapp MLD, and J A (ed) The SAGE Handbook of Interpersonal Communication. London: Sage.

Clark C. (1997) Misery and company: Sympathy in everyday life, Chicago: University of Chicago Press.

Collins R. (2004) Interaction Ritual Chains, Princeton: Princeton University Press.

Collins R. (2008) Violence: A micro-sociological theory, Princeton: Princeton University Press.

Darley JM and Latané B. (1968) Bystander intervention in emergencies: diffusion of responsibility. Journal of Personality and Social Psychology 8: 377-383.

de Waal FBM and van Roosmalen A. (1979) Reconciliation and consolation among chimpanzees. Behavioral Ecology and Sociobiology 5: 55-66.

Eagly AH. (2009) The his and hers of prosocial behavior: an examination of the social psychology of gender. American Psychologist 64: 644-658.

Fischer P, Krueger JI, Greitemeyer T, et al. (2011) The bystander-effect: a meta-analytic review on bystander intervention in dangerous and non-dangerous emergencies. Psychological bulletin 137: 517-537.

Goffman E. (1961) Encounters: Two studies in the sociology of interaction, Indianapolis: Bobbs-Merrill.

Goffman E. (1971) Relations in Public. Microstudies of the Public Order, New York: Basic Books.

Grady MP. (1998) Qualitative and action research: A practitioner handbook: Phi Delta Kappa International. 
Greitemeyer T and Mügge DO. (2015) When bystanders increase rather than decrease intentions to help. Social Psychology 46: 116-119.

Heinskou MB and Liebst LS. (2016) On the Elementary Neural Forms of MicroInteractional Rituals: Integrating Autonomic Nervous System Functioning Into Interaction Ritual Theory. Sociological Forum 31: 354-376.

Jackson-Jacobs C. (2013) Constructing physical fights: An interactionist analysis of violence among affluent, suburban youth. Qualitative sociology 36: 23-52.

King G, Keohane RO and Verba S. (1994) Designing social inquiry: Scientific inference in qualitative research: Princeton university press.

Levine M, Lowe R, Best R, et al. (2012) 'We police it ourselves': group processes in the escalation and regulation of violence in the night-time economy. European journal of social psychology 42: 924-932.

Levine M, Taylor PJ and Best R. (2011) Third parties, violence, and conflict resolution: The role of group size and collective action in the microregulation of violence. Psychological Science 22: 406-412.

Liebst LS, Heinskou MB and Ejbye-Ernst P. (2018) On the Actual Risk of Bystander Intervention: A Statistical Study Based on Naturally Occurring Violent Emergencies. Journal of Research in Crime and Delinquency. 55: 155-186.

Lindegaard MR and Bernasco W. (2018) Lessons Learned from Crime Caught on Camera. Journal of Research in Crime and Delinquency. 55: 155-186.

Lindegaard MR, Liebst LS, Bernasco W, et al. (2017) Consolation in the aftermath of robberies resembles post-aggression consolation in chimpanzees. PLOS ONE 12: $\mathrm{e} 0177725$.

Milgram S and Toch H. (1969) Collective behavior: Crowds and social movements. In: Linzey G and Aronson E (eds) Handbook of Social Psychology. Reading: Addison Wesley, 507-610.

Nassauer A and Legewie N. (2016) Visual Data Analysis: Towards a Methodological Framework for a Novel Trend in Studying Behavior. Paper presented at the American Sociological Association Annual Meeting, Seattle, USA.

Philpot R. (2017) Beyond the Dyad: The Role of Groups and Third-Parties in the Trajectory of Violence. Exeter: University of Exeter. 
Scheff TJ. (1994) Microsociology: Discourse, emotion, and social structure, Chicago: University of Chicago Press.

Solomon LZ, Solomon H and Stone R. (1978) Helping as a function of number of bystanders and ambiguity of emergency. Personality and Social Psychology Bulletin 4: 318-321.

Valach L, von Cranach M and Kalbermatten U. (1988) Social meaning in the observation of goal directed action. Semiotica 71: 243-260.

von Cranach M, Kalbermatten U, Indermühle K, et al. (1982) Goal-directed action, London: Academic Press.

Vrij A, Hope L and Fisher RP. (2014) Eliciting reliable information in investigative interviews. Policy Insights from the Behavioral and Brain Sciences 1: 129-136. 